\title{
Comparative Transcriptomic Analysis of Plum Fruit Treated with 1-MCP
}

\author{
G.A. Manganaris \\ Cyprus University of Technology \\ Department of Agricultural Production \\ and Food Science and Technology \\ Lemesos \\ Cyprus \\ V. Ziosi and G. Costa \\ Dipartimento di Colture Arboree \\ University of Bologna \\ Via Fanin 46, 40127, Bologna \\ Italy
}

\section{J.B. Golding}

New South Wales Department of Primary Industries, Gosford Horticultural Institute Locked Bag 26, Gosford, NSW 2250

Australia

\author{
A. Jajo, P. Holford, M.R. Jones and \\ B. McGlasson \\ University of Western Sydney \\ Locked Bag, Penrith South DC, NSW \\ Australia
}

\author{
A. Rasori, A. Ramina and C. Bonghi \\ (Padova) \\ Italy \\ P. Tonutti \\ Scuola Superiore Sant'Anna \\ Piazza Martiri della Libertà 33 \\ 56127 Pisa \\ Italy
}

Department of Environmental Agronomy

and Crop Science, University of Padova

Viale dell'Università 16, 35020 Legnaro

Keywords: genomics tools, oligonucleotide hybridization, fruit ripening, Prunus persica, Prunus salicina, ethylene climacteric, chilling injury, physiological disorders

\begin{abstract}
Microarray technology has allowed the large scale transcriptomic analysis of fruit ripening. The $\mu$ PEACH1.0 microarray containing 4,806 probes corresponding to genes expressed in peach fruit tissues has been used in a heterologous fashion in two studies of plums ripening behavior. Gene expression of different cultivars of plums treated with the ethylene antagonist, 1-methylcyclopropene (1-MCP) and stored for short periods at room temperature or for longer periods of cold storage was examined. In the first study, mature fruit of a suppressed ethylene climacteric cultivar 'Shiro' and a cultivar characterized by a typical increase of ethylene production during ripening ('Santa Rosa') were harvested and incubated for $24 \mathrm{~h}$ in air (control) or 1-MCP and allowed to ripen at room temperature. Different levels of transcripts of genes implicated in cell wall metabolism, hormone (ethylene and auxin) regulation, stress and defense, and in the transcription/translation machinery, as well as others involved with ripening were identified. In the second study, the effects of 1-MCP on gene expression in relation to the development of chilling injury (CI) in the climacteric cultivars 'Ruby Red' (RR) and 'October Sun' (OS) and 'Zee Lady' peaches (ZP) were analyzed. The fruit were treated for $24 \mathrm{~h}$ at room temperature with 1-MCP prior to storage at $0^{\circ} \mathrm{C}$. For $\mathrm{RR}$, there was no significant effect of 1-MCP on the level of CI symptoms, while 1-MCP significantly reduced $C I$ symptoms in $O S$ fruit and an increase of $C I$ in treated $Z P$ fruit. Microarray analysis showed that immediately following treatment, 186, 134 and 56 genes were differentially expressed between the control and 1-MCP-treated fruit of these cultivars, respectively: after 4 weeks cold storage, 311, 52 and 224 genes for $R R$, OS and ZP, respectively, were differentially expressed between control and treated fruit. Thus, for OS, the number of differentially expressed genes reduced during storage while the number increased in $R R$ and $Z P$. Comparisons of the data suggest that the transcript profile is altered by 1-MCP more in plums than peaches. These studies, carried out within an international collaborative network, will increase our understanding of the regulation of pathways involved in plum fruit ripening and in metabolic processes related to storage and shelf life.
\end{abstract}




\section{INTRODUCTION}

1-methylcyclopropene (1-MCP), is an influential chemical compound both in technological (applied) aspects for maintaining fruit quality and in order to elucidate the role of ethylene in fruit ripening and other developmental processes (Watkins, 2006).

Plum fruit is a highly perishable commodity with a relatively short shelf life, however, differences in terms of ripening properties exist and plum cultivars are categorized as suppressed-climacteric and climacteric cultivars (Abdi et al., 1998). In addition, plum fruit are susceptible to the incidence of chilling injury (CI) symptoms after removal from cold storage. Although these constrains represent a strong limitation to market life, research has been focused on the identification of the symptoms and strategies to alleviate CI (Crisosto et al., 2004; Manganaris et al., 2008), while no information at molecular level is available. Application of 1-MCP in plums showed that its postharvest life can be extended after harvest or after removal from cold storage due to both a delay of ripening processes and, in some cases, a reduced incidence of CI disorders (Martinez-Romero et al., 2003; Manganaris et al., 2007; Khan and Singh, 2008, 2009). However, in peach, a related species, 1-MCP has been shown to have limited effect in maintaining fruit quality and increased incidence of CI following treatment and cold storage (Girardi et al., 2005; Dal Cin et al., 2006; Ziliotto et al., 2008).

In the current study the effect of 1-MCP alone or combined with cold storage on plum fruit with diverse ripening properties was studied at a transcriptome level. For transcriptomic studies the first available peach microarray ( $\mu$ PEACH1.0) (Trainotti et al., 2006) was used in a heterologous and comparative fashion.

\section{MATERIALS AND METHODS}

Mature fruit of 'Shiro' plums (SH, suppressed ethylene climacteric) and 'Santa Rosa' (SR, climacteric) were harvested and incubated for $24 \mathrm{~h}$ in air (control) or 1-MCP $\left(1 \mu \mathrm{L}^{-1}\right)$. After treatment fruit were allowed to ripen at room temperature for 3 days. Data obtained from earlier studies (Ziliotto et al., 2008) in nectarine fruit ('Fantasia') were used in order to define plum-specific, peach-specific or genes that showed a similar expression pattern in both species during postharvest ripening.

In a different experiment, the effects of $1-\mathrm{MCP}$ on gene expression in relation to the development of CI in the climacteric cultivars 'Ruby Red' (RR) and 'October Sun' (OS) were analyzed also in comparison with the peach 'Zee Lady' (ZP). Fruits were treated for $24 \mathrm{~h}$ at room temperature with 1 -MCP $\left(625 \mathrm{nl} \mathrm{L}^{-1}\right)$ prior to cold storage at $0^{\circ} \mathrm{C}$ for 4 weeks.

RNA was isolated according to Bonghi et al. (1998). In order to remove contaminant DNA from the RNA samples, the nucleic acid extract was treated with DNase (RQ1, Promega), according to the manufacturer's instructions. Absorbance at $260 \mathrm{~nm}$ was used to measure the concentration of RNA and its integrity was checked on agarose gel. RNA conversion into target cDNA, microarray hybridization, and data analysis were carried out as described by Trainotti et al. (2007). Genes showing $\log _{2}$ ratio either $>1$ (up-regulated) or $<-1$ (down-regulated) were annotated following the Gene Ontology categories (GO) developed by TAIR.

\section{RESULTS AND DISCUSSION}

\section{Effects of 1-MCP after Treatment}

At the end of the treatment, no differentially expressed genes were identified in common to the two plum cultivars SH and SR, and between SH and F nectarine (Fig. 1). Considering SR and F fruit, 10 and 15 genes induced or repressed by 1-MCP at the end of treatment, respectively, were common to both cultivars (Fig. 1). After treatment, the inhibitory effect of 1-MCP was maintained for SR fruit, while in 'Fantasia' a marked recovery of transcription was observed for many genes including some involved in the ethylene perception, auxin-action and cell wall metabolism. These genes could be responsible for the different effects of 1-MCP observed in climacteric peach and plum 
cultivars.

\section{Effects of 1-MCP after Removal from Cold Storage}

For RR, there was no significant effect of 1-MCP on the level of chilling injury while for OS 1-MCP significantly reduced CI. Microarray analysis showed that immediately following treatment, among genes identified after SAM analysis (186 and 134 for control and 1-MCP-treated fruit of RR and OS, respectively) those already identified by the first approach (Table 1) were also present. After 4 weeks of cold storage, the number of genes in OS decreased, while they increased in RR. Comparison of these microarray data with those obtained from peaches $(\mathrm{ZP})$ suggests that the transcript profile is altered in plums by 1-MCP more than in peaches. Among the genes showing upregulation after 4 weeks, some were involved in temperature-stress responses in all genotypes, in gamma-aminobutyrate acid (GABA) metabolism ( $\gamma_{\text {-aminobutyrate }}$ transaminase) only in RR and OS and in some components of a redox-system responsible for cold-resistance. This latter gene, in addition to others already identified with roles in cell wall metabolism, membrane permeability, endomembrane trafficking, could be involved in the development of resistance to CI symptoms.

\section{CONCLUSIONS}

Overall, this preliminary transcriptomic approach suggests that the peach microarray can be employed in a heterologous fashion for plum fruit where relatively few data regarding gene expression during fruit ripening exist. Further experiments should be carried out in order to shed light on plum ripening after harvest or after removal from cold storage. The existence of plum cultivars with different ripening properties in terms of ethylene production, along with the available knowledge in peach fruit ripening can be used to define common or divergent mechanisms between the two related, yet phenotypically distinct species.

\section{ACKNOWLEDGEMENTS}

G.A. Manganaris is a recipient of an E.U. Marie Curie individual fellowship (Grant MEIF-CT-2006-038997).

\section{Literature Cited}

Abdi, N., McGlasson, W.B., Holford, P., Williams, M. and Mizrahi, Y. 1998. Responses of climacteric and suppressed-climacteric plums to treatment with propylene and 1methylcyclopropene. Postharvest Biol. Technol. 14:29-39.

Bonghi, C., Ferrarese, L., Ruperti, B., Tonutti, P. and Ramina, A. 1998. Endo-beta-1,4glucanases are involved in peach fruit growth and ripening, and regulated by ethylene. Physiologia Plant. 102:346-352.

Crisosto, C.H., Garner, D., Crisosto, G.M. and Bowerman, E. 2004. Increasing 'Blackamber' plum (Prunus salicina Lindell) consumer acceptance. Postharvest Biol. Technol. 34:237-244.

Dal Cin, V., Rizzini, F.M., Botton, A. and Tonutti, P. 2006. The ethylene biosynthetic and signal transduction pathways are differently affected by 1-MCP in apple and peach fruit. Postharvest Biol. Technol. 42:125-133.

Girardi, C.L., Corrent, A.R., Lucchetta, L., Zanuzo, M.R., da Costa, T.S., Brackmann, A., Twyman, R.M., Nora, F.R., Nora, L., Silva, J.A. and Rombaldi, C.V. 2005. Effect of ethylene, intermittent warming and controlled atmosphere on postharvest quality and the occurrence of woolliness in peach (Prunus persica cv. Chiripa) during cold storage. Postharvest Biol. Technol. 38:25-33.

Khan, A.S. and Sing, Z. 2008. 1-Methylcyclopropene application and modified atmosphere packaging affect ethylene biosynthesis, fruit softening, and quality of 'Tegan blue' Japanese plum during cold storage. J. Amer. Soc. Hortic. Sci. 133:290299.

Khan, A.S. and Sing, Z. 2009. 1-MCP application suppresses ethylene biosynthesis and 
retards fruit softening during cold storage of 'Tegan Blue' Japanese plum. Plant Sci. 176:539-544.

Manganaris, G.A., Vicente, A.R., Crisosto, C.H. and Labavitch, J.M. 2007. Effect of dips in a 1-methylcyclopropene-generating solution on 'Harrow Sun' plums stored under different temperature regimes. J. Agric. Food Chem. 55:7015-7020.

Manganaris, G.A., Vicente, A.R., Crisosto, C.H. and Labavitch, J.M. 2008. Cell wall modifications in chilling-injured plum fruit (Prunus salicina). Postharvest Biol. Technol. 48:77-83.

Martinez-Romero, D., Dupille, E., Guillen, F., Valverde, J.M., Serrano, M. and Valero, D. 2003. 1-Methylcyclopropene increases storability and shelf life in climacteric and nonclimacteric plums. J. Agric. Food Chem. 51:4680-4686.

Trainotti, L., Bonghi, C., Ziliotto, F., Zanin, D., Rasori, A., Casadoro, G., Ramina, A. and Tonutti, P. 2006. The use of microarray $\mu$ PEACH1.0 to investigate transcriptome changes during transition from pre-climacteric to climacteric phase in peach fruit. Plant Sci. 170:606-613.

Trainotti, L., Tadiello, A. and Casadoro, G. 2007. The involvement of auxin in the ripening of climacteric fruits comes of age: The hormone plays a role of its own and has an intense interplay with ethylene in ripening peaches. J. Exp. Bot. 58:3299-3308.

Watkins, CB. 2006. The use of 1-methylcyclopropene (1-MCP) on fruits and vegetables. Biotechnol. Adv. 24:389-409.

Ziliotto, F., Begheldo, M., Rasori, A., Bonghi, C. and Tonutti, P. 2008. Transcriptome profiling of ripening nectarine (Prunus persica L. Batsch) fruit treated with 1-MCP. J. Exp. Bot. 59:2781-2791.

\section{$\underline{\text { Tables }}$}

Table 1. Number of genes differentially expressed by comparing untreated and treated fruit at time 0 (T0) and after four weeks.

\begin{tabular}{lrc}
\hline Variety & T0 & 4 weeks storiage $\left(0^{\circ} \mathrm{C}\right)$ \\
\hline 'October Sun' plums (OS) & 134 & 52 \\
'Ruby Red' plums (RR) & 186 & 311 \\
'Zee Lady' peaches (ZP) & 56 & 224 \\
\hline
\end{tabular}



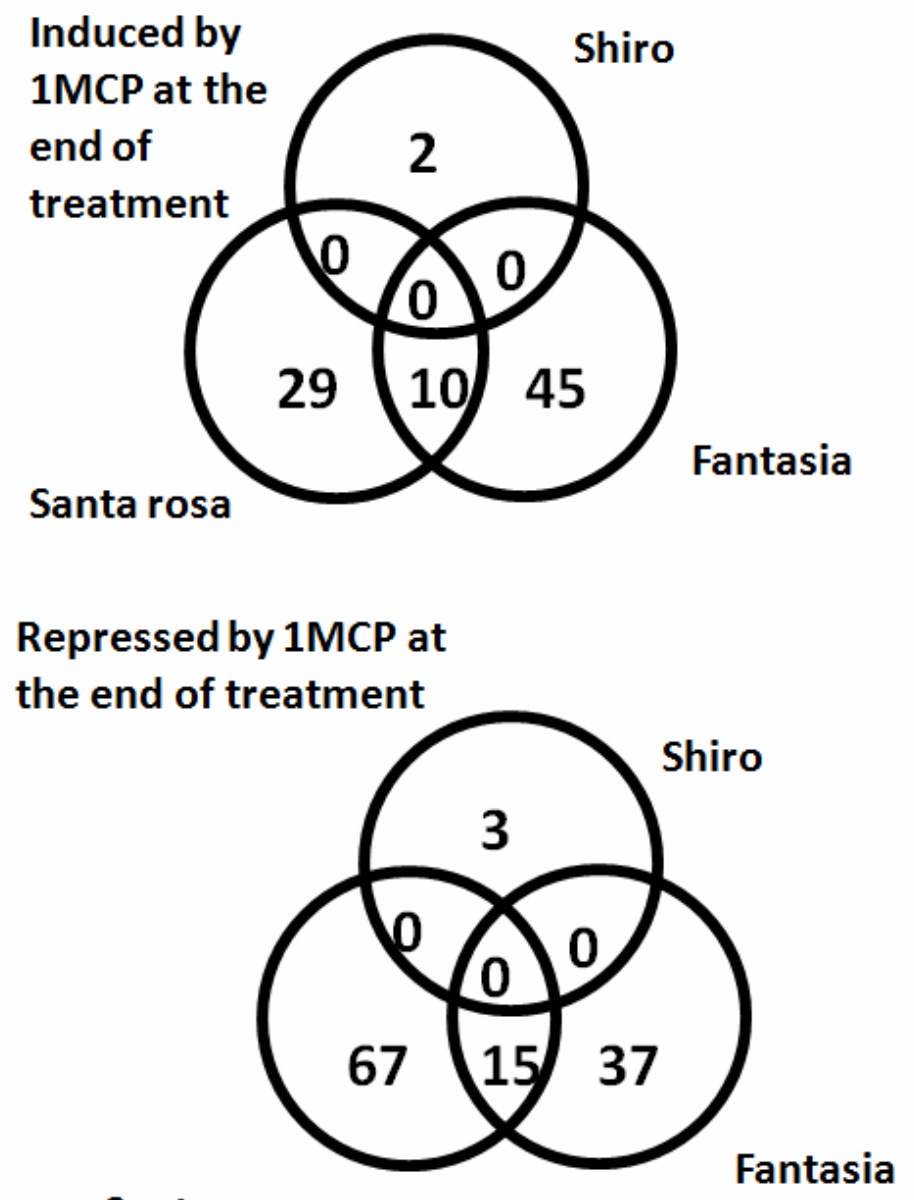

Santa rosa

Fig. 1. The Venn diagrams show the numbers of differentially expressed genes (induced, top and repressed, bottom) at the end of the 1-MCP treatment in 'Shiro', 'Santa Rosa' and 'Fantasia'. 
